Research Article

\title{
Finite Element Analysis of Temperature Distribution and Stress Behavior of Squeeze Pressure Composites
}

\author{
P. Gurusamy, ${ }^{1}$ T. Sathish $\mathbb{D}^{2},{ }^{2}$ V. Mohanavel $\mathbb{D},{ }^{3}$ Alagar Karthick $\mathbb{D}^{\circ},{ }^{4}$ M. Ravichandran $\mathbb{D}^{\circ},{ }^{5}$ \\ Omaima Nasif, ${ }^{6}$ Saleh Alfarraj, ${ }^{7}$ Velu Manikandan, ${ }^{8}$ and S. Prasath $\mathbb{D}^{9}$ \\ ${ }^{1}$ Department of Mechanical Engineering, Chennai Institute of Technology, Chennai 600069, India \\ ${ }^{2}$ Department of Mechanical Engineering, Saveetha School of Engineering, SIMATS, Chennai 602105, Tamilnadu, India \\ ${ }^{3}$ Centre for Materials Engineering and Regenerative Medicine, Bharath Institute of Higher Education and Research, \\ Chennai 600073, Tamilnadu, India \\ ${ }^{4}$ Department of Electrical and Electronics Engineering, KPR Institute of Engineering and Technology, Coimbatore 641407, \\ Tamilnadu, India \\ ${ }^{5}$ Department of Mechanical Engineering, K. Ramakrishnan College of Engineering, Tiruchirappalli 621112, Tamilnadu, India \\ ${ }^{6}$ Department of Physiology, College of Medicine and King Khalid University Hospital, King Saud University Medical City, \\ P.O. Box 2925, Riyadh 11461, Saudi Arabia \\ ${ }^{7}$ Zoology Department, College of Science, King Saud University, Riyadh 11451, Saudi Arabia \\ ${ }^{8}$ College of Environmental \& Bioresource Sciences, Jeonbuk National University, Iksan 570752, Republic of Korea \\ ${ }^{9}$ Department of Mechanical Engineering, College of Engineering and Technology, Mizan Tepi University, \\ Tepi Campus, Tepi 121, Ethiopia
}

Correspondence should be addressed to S. Prasath; prasath@mtu.edu.et

Received 8 July 2021; Revised 7 August 2021; Accepted 20 August 2021; Published 27 September 2021

Academic Editor: Jinyang Xu

Copyright ( $\odot 2021 \mathrm{P}$. Gurusamy et al. This is an open access article distributed under the Creative Commons Attribution License, which permits unrestricted use, distribution, and reproduction in any medium, provided the original work is properly cited.

Aluminium-reinforced composites play a vital role in the engineering industry because of their better strength and stiffness. The properties are directly related to the solidification phenomenon of the cast alloy. The design engineer should understand the importance of the solidification behavior of base alloy and its reinforcement. Composites' solidification study is rare, and the reviews are limited. The solidification process is analyzed using the finite element method (FEM), and this would fetch a lot of information about the cooling rate of the composites and also helps to reduce the time in experimentation. This paper reports and plots the cooling curves of $\mathrm{Al} / \mathrm{SiC}_{p}$ composites using simulation software. Cylindrical-shaped composites were developed using the squeeze casting method, and the experimental cooling curves were plotted using a K-type thermocouple. Composites samples were prepared at the following squeeze pressures: $0,30,50,70,100$, and $130 \mathrm{MPa}$; melt and die temperature was kept constant at 800 and $400^{\circ} \mathrm{C}$, respectively. The experimental and FEA cooling curves were compared, and it was agreed that the increase in the squeeze pressure increases the cooling rate of the developed composite. Furthermore, the effect of temperature distribution from the inner region of the melt and die material which causes the radial and tangential stress of components has also been examined.

\section{Introduction}

Aluminium alloys, reinforced with $\mathrm{SiC}$, have become an essential material that is used in a wide range of applications in the aviation, marine, electronic packaging, defence, and automobile industries [1]. The nature of the matrix metal is generally soft which contains good mechanical and thermal properties. The most common metals are aluminium, copper, titanium, magnesium, etc. The standard properties offered by the metals are malleability, ductility, fatigue strength, machinability, and thermal and electrical conductivity. The reinforcing material has to offer strong bonding to the metal in order to make the composite tensile, and the stiffness to weight ratio and strength to weight ratio is higher than the metal matrices. The hard and robust nature is obtained when the correct amount of the 
reinforcements is added to the matrix. The particle-reinforced metal matrix composites exhibit better physical and mechanical properties; it can be modified to reach metallurgist requirements. Also, this material can show excellent thermophysical properties due to which it has been used in all the structural applications. It can pose a tremendous amount of strength at high-temperature applications; the capability to reveal low thermal shock and excellent wear resistance at less weight is the unique characteristics. There are many manufacturing methods to produce MMCs on which solid- and liquid-state processing is the promising route for developing the composites [2]. In solid-state processing, the interfacial reaction between base alloy and ceramic particles is not right in agreement. Hence, liquidstate processing can resolve this issue through stir casting. Further improving the better properties of the composites, the process adopts the squeeze casting method. It is a method to remove shrinkage and porosity during the liquidstate processing of composites. Hence, near net shape components are fabricated by this method [3].

Ghomashchi and Vikhrov [4] reported that the essential parameters for fabricating any alloys using squeeze casting routes are melt temperature, die temperature, and application of pressure, the main premise for this research. The base alloy's temperature, heat transfer coefficient, thermal conductivity, die temperature, and pressure during solidification would change the phase relationship of any alloy system. Thus, the application of pressure helps to decrease the interatomic movement during the process of solidification, which allows changes in the temperature of the melt. Many other factors would influence increase of the pressure, which are impurities, trace elements, and intersolubility of constituents' elements. Yue and Chadwick [5] have observed that the application of pressure would reduce the gap between the mould and melt, which leads to a more significant cooling rate. It influences the cooling rate. In permanent mould casting, due to the surface contact between the mould and casting, the cooling rate and solidification time must be considered for better results [6]. The mechanical properties of the casting are derived from the solidification time of the casting. Sukumaran et al. [7] investigated the squeeze cast A2124 alloy with $10 \%$ ceramic particles with increasing pressure during solidification of alloy and the developed composite. He reported that the application of pressure directly relates to the enhancement of composites. The applied pressure of about $100 \mathrm{MPa}$ has created uniform particle distribution and other factors such as porosity and shrinkages and obtained fine refinement of microstructure. Furthermore, he reported that the squeeze pressure coupled with die temperature is increased; the heat transfer rate in composites is higher compared with that of the base alloy. The heat transfer rate is directly related to the amount of particles present in the alloys, which decides the cooling rate of the composite. Hanumanth and Irons [8] have reported that particle distribution can increase the cooling rate up to a certain percentage of reinforcing particles; after that, the cooling rate is decreased. Increasing the particles reduces the heat transfer rate in the melt, which causes the thermal diffusivity of the composite to reduce. Studies by Rajan et al. [9] have shown varying volume fractions of graphite and $\mathrm{SiC}$ particles with AA6082 alloy in the sand, steel, and graphite moulds, and heat transfer at casting and mould interface is also investigated. The heat transfer rate is enhanced due to the addition of one percent of magnesium particles in the aluminium alloy; this increases the wettability between the particle and the base alloy. The magnesium particles can be useful for hunting the oxide layer as well as increasing the interfacial reaction between the melt and the mould. Many researchers found, during the study of interfacial reaction, that the effect of intermetallic compounds plays a vital role. Zhou [10] reveals that the intermetallic compounds $\left(\mathrm{Al}_{4} \mathrm{C}_{3}\right)$ would decrease when the solidification process is disturbed, which means it affects the fluidity of the materials. The compunds are varied with respect to the base alloy. Studies on $\mathrm{Al}$ and Graphene-bonding strength and wettability literature are not enough so far, these two intermetallic compounds, such as $\mathrm{Al}_{4} \mathrm{C}_{3}$ and $\mathrm{Al}_{2} \mathrm{O}_{3}$, are helping the base alloy in terms of transferring loads [10-12]. Li et al. [13] claimed that no evidence had noticed the formation of $\mathrm{Al}_{4} \mathrm{C}_{3}$ between $\mathrm{Al}$ and graphene nanoplatelets (GNPs). Nonetheless, stacking faults were observed near the $\mathrm{Al}$ matrix, which could be the reason for the strengthening of composites. Incorporating metal reinforcement (Cu-GNPs and Ni-GNPs) along with GNPs would enhance the strength of the composite; perhaps, the metal particles could have stopped the formation of $\mathrm{Al}_{4} \mathrm{C}_{3}$ [14]. Liu et al. [15] reported that the application of pressure would enhance the interface strength of $\mathrm{Al} / \mathrm{Mg}$ based composites. The intermetallic compounds are directly related to the cooling rate of the composites, and the application of squeeze pressure enhances the cooling rate of the composite [16]. The effect of intermetallic compound $\left(\mathrm{Al}_{4} \mathrm{C}_{3}\right)$ is modeled with the help of Ansys software, and the impact of that is compared with the rule of mixture predictions. No significant results have been found in the AlSi/CNT composites [17].

There are many studies based on fracture behaviour, interpenetrating with some structure models, simulation of moulds [18, 19], addition of particles with base alloy [20-22], and mechanical properties of particles [23-25] and using the finite element method. The study based on the solidification and cooling rate of the composites is highly complicated. Because, during the solidification process, the complex shapes' grain refinement and the features of microstructures are changed. Also, there are many studies which are focused only on the base alloy cooling rate and solidification process. This study gives importance of two different materials' solidification process because of its different behaviours. Hence, the squeeze casting process would give better results and integrate the cooling rate and microstructural features. There is a lack of information regarding the application pressure on the solidification study of cast composites, which is an essential feature in the high-pressure die casting industry. Therefore, the present work focuses on both experimental and theoretical research on the solidification of AA6082 composites with temperature behaviour and stress behaviour using the finite element method. 


\section{Boundary Conditions for the Cylindrical Model}

The cooling curves have been plotted by the simulation software-ANSYS (version 19.2). Structural analysis, followed by thermal analysis, is carried out by the coupled field analysis. Hence, the structural and thermal capability of the element (PLANE 13) is used. Thus, each node has up to fourdegree degrees of freedom. In this study, first, nonlinear thermal analysis was carried out, and then, static stress analysis was carried out. The half portion of a cylinder with the melt model was plotted for this symmetrical problem. Figure 1 shows the two-dimensional model of casting with the melt with its dimensions. The thermophysical properties of ceramic materials and AA6082 are shown in Table 1. The processing conditions for the preparation of cast samples are listed in Table 2. Tables 3 and 4 show die and ceramic material properties $[9,26]$. Table 5 shows the boundary conditions of the FEA model. Convection properties were initially given to the model, and the initial room temperature is also applied to the die wall. Figure 2(a) shows the model for melt and die without boundary conditions, and Figure 2(b) shows the convection boundary condition for the die material. The rule of mixture was used to calculate the thermal conductivity of the composite. In contrast, the value of enthalpy is considered as the same value of base alloy because there is no phase change or ceramic material [22]. A step-by-step process of the solidification process concerning time is established by solution control. Finally, the cooling curve is plotted with the help of a time-history processor.

\section{Experimental Work}

The base plate width was $120 \mathrm{~mm}$, the die inner diameter was $50 \mathrm{~mm}$, thickness was $35 \mathrm{~mm}$, and height was $150 \mathrm{~mm}$. Figure 3(a) shows the melt stirring with reinforcement setup, and Figure 3(b) shows the punch and die have been preheated. Figure 4(a) shows the baseplate and die, and Figure 4(b) shows the appropriate locations of thermocouples. Figure 4(c) shows the fabrication of the squeeze cast setup. The squeeze casting technique was adopted for fabricating the composites, as discussed in [3]. The temperature values were being recorded by K-type thermocouple, which was recorded every one second. Figure 4(d) shows the thermocouples in its exact locations. The data acquisition system was incorporated in the experimental setup to record all temperature values, precisely. The recorded values were transferred to the computer to draw solidification curves. Aluminium composites were fabricated with increasing pressures when the die and melt temperatures were 400 and $800^{\circ} \mathrm{C}$, respectively.

\section{Results and Discussion}

4.1. Cooling Rate and Time. The temperature readings measured from the baseplate readings $\left(T_{0}\right.$ to $\left.T_{2}\right)$ are used to plot cooling curves and solidification time. In contrast, the die materials' temperature readings $\left(T_{3}\right.$ to $\left.T_{5}\right)$ are used to measure the temperature distribution of the die. The

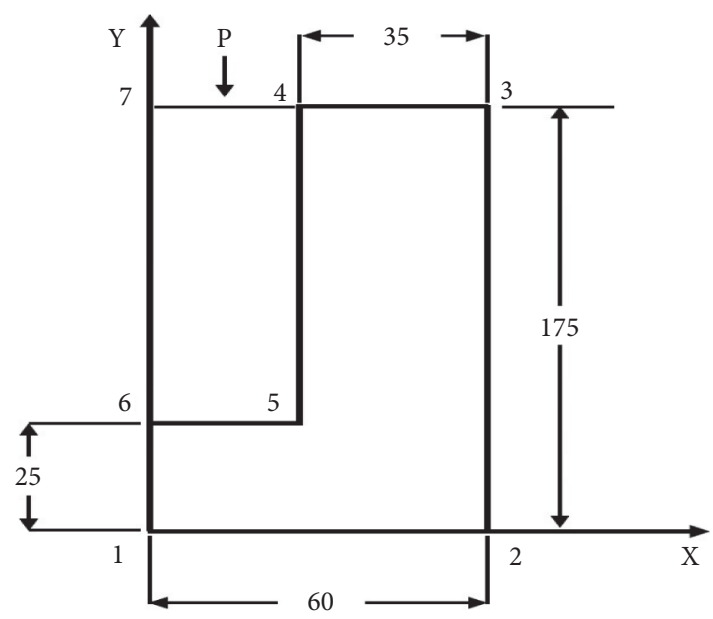

FIGURE 1: The cylindrical model with BCs for the die temperature of $400^{\circ} \mathrm{C}$ (melt temperature $800^{\circ} \mathrm{C}$ and pressure $130 \mathrm{MPa}$ ).

TABLE 1: Chemical composition of AA6082 aluminium alloy.

\begin{tabular}{lllllllllll}
\hline Element & $\mathrm{Si}$ & $\mathrm{Fe}$ & $\mathrm{Cu}$ & $\mathrm{Mn}$ & $\mathrm{Mg}$ & $\mathrm{Cr}$ & $\mathrm{Zn}$ & $\mathrm{Ti}$ & $\mathrm{Al}$
\end{tabular}

\begin{tabular}{llllllllll}
\hline Weight (\%) & 1.0 & 0.60 & 0.10 & 0.5 & 0.7 & 0.25 & 0.10 & 0.20 & $\mathrm{Bal}$ \\
\hline
\end{tabular}

TABle 2: Process conditions for composites.

\begin{tabular}{lcc}
\hline Die temperature $\left({ }^{\circ} \mathrm{C}\right)$ & $\begin{array}{c}\text { Matrix } \\
\text { temperature }\left({ }^{\circ} \mathrm{C}\right)\end{array}$ & $\begin{array}{c}\text { Pressure } \\
(\mathrm{MPa})\end{array}$ \\
\hline 400 & 800 & $0,30,50,70,100,130$ \\
\hline
\end{tabular}

temperature readings are used to determine the solidification time for any type of cast alloy [26].

Increasing the pressure decreases the solidification time from 60 seconds to 42 seconds [2]. Figure 5 shows the various squeeze pressures cooling curves for both experiment and FEA study of $\mathrm{Al} / \mathrm{SiCp}$ composite. The cooling rate is observed from the experimental cooling curves, and the values are $2.28^{\circ} \mathrm{C} / \mathrm{s}$ $2.52^{\circ} \mathrm{C} / \mathrm{s}, 2.68^{\circ} \mathrm{C} / \mathrm{s}, 2.87^{\circ} \mathrm{C} / \mathrm{s}, 3.5^{\circ} \mathrm{C} / \mathrm{s}$, and $3.75^{\circ} \mathrm{C} / \mathrm{s}$ for $0,30,50$, 70,100 , and $130 \mathrm{MPa}$, respectively. The flattening region is the freezing zone, and it is clearly shown in Figure 5.

The melting range of AA6082 alloy in the solid state is $577^{\circ} \mathrm{C}$ and the liquid state is $615^{\circ} \mathrm{C}$, and the experimental freezing range is closely agreed with that of Hanumanth and Irons [8]. Also, in squeeze casting, the application of pressure brings the melt to solidify first, and then, the cooling rate is decided by the location of the particle [27]. Maleki et al. [28] reported that the application of pressure enhances the die and melt contact surface, which promotes high heat transfer and cooling rate. Hence, increasing the pressure increases the cooling rate of the composite. The predicted cooling rates are $1.23^{\circ} \mathrm{C} / \mathrm{s}, 1.31^{\circ} \mathrm{C} / \mathrm{s}, 1.47^{\circ} \mathrm{C} / \mathrm{s}$, $1.81^{\circ} \mathrm{C} / \mathrm{s}, 1.98^{\circ} \mathrm{C} / \mathrm{s}$, and $2.24^{\circ} \mathrm{C} / \mathrm{s}$ for the squeeze pressure of 0 , $30,50,70,100$, and $130 \mathrm{MPa}$, respectively. Particle and base alloy reaction, formation of air inside the mould and melt, aspirations, and flow velocity were not considered in this analysis. The mentioned factors have to be considered for the FEA study [22], even though the cooling rate is almost close to the experimental cooling rate. 
TABle 3: Properties of SiC [9].

\begin{tabular}{lccc}
\hline Material & Thermal conductivity $\left(\mathrm{W} / \mathrm{m}^{\circ} \mathrm{C}\right)$ & Density $\left(\mathrm{kg} / \mathrm{m}^{3}\right)$ & Specific heat $(\mathrm{J} / \mathrm{kg} \cdot \mathrm{k})$ \\
\hline Silicon carbide & 100 & 3200 & 1300
\end{tabular}

TABle 4: Properties of H13 [26].

\begin{tabular}{lccc}
\hline Material & Thermal conductivity $\left(\mathrm{W} / \mathrm{m}^{\circ} \mathrm{C}\right)$ & Density $\left(\mathrm{kg} / \mathrm{m}^{3}\right)$ & Specific heat $(\mathrm{J} / \mathrm{kg} \cdot \mathrm{k})$ \\
\hline AISI H13 & 28.6 & 7761 & 461 \\
\hline
\end{tabular}

TABLE 5: Boundary conditions for the applied pressure of $130 \mathrm{MPa}$.

\begin{tabular}{lcc}
\hline Key points & Variables $(\mathrm{mm})$ & Parameters $\left({ }^{\circ} \mathrm{C}\right)$ \\
\hline 1 & $x=0 ; y=0$ & $T_{d}=400$ \\
2 & $x=60 ; y=0$ & $T_{d}=400$ \\
3 & $x=60 ; y=175$ & $T_{d}=400$ \\
4 & $x=25 ; y=175$ & $T_{m}=800$ \\
5 & $x=25 ; y=25$ & $T_{m}=800$ \\
6 & $x=0 ; y=25$ & $T_{m}=800$ \\
7 & $x=0 ; y=175$ & $T_{m}=800$ \\
\hline
\end{tabular}

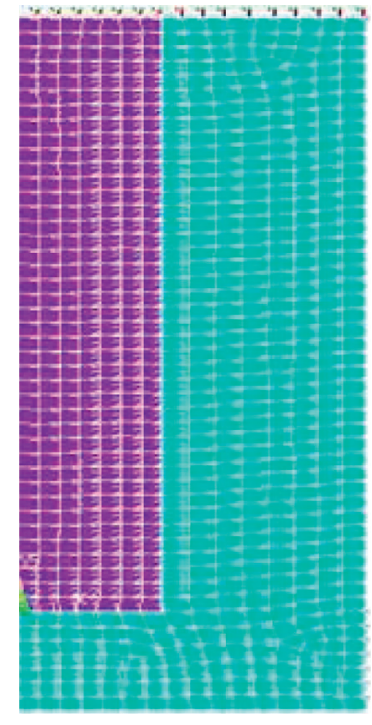

(a)

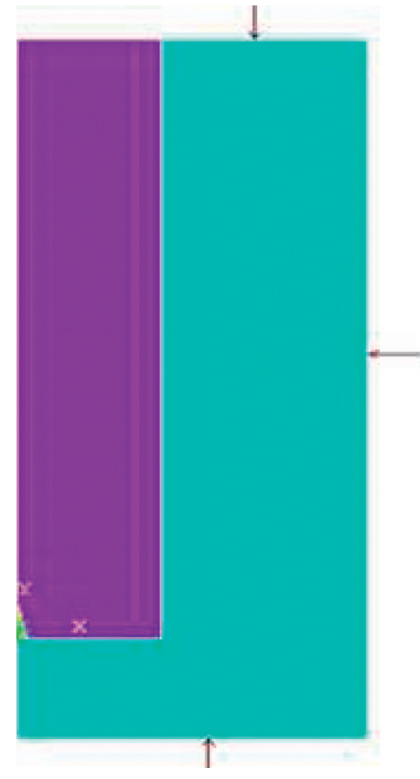

(b)

Figure 2: (a) FEA model of melt and die without BCs. (b) Convection boundary conditions of the FEA model.

4.2. Temperature Distribution and Thermal Stresses. To avoid multiple trial-and-error casting production or to avoid recreating the system repeatedly, the FEA-based analysis is recommended to fulfill the technical problems $[13,14]$. Temperature distribution within the melt and distribution in the die are essential factors to identify the rate of the solidification process, mainly when the melt is in the application of pressure. Figure 6 shows the temperature dispersion in the composites at various squeeze pressures up to 800 seconds. From the FEA analysis, the observed values are $314^{\circ} \mathrm{C}, 318^{\circ} \mathrm{C}, 319^{\circ} \mathrm{C}, 321^{\circ} \mathrm{C}, 322^{\circ} \mathrm{C}$, and $323^{\circ} \mathrm{C}$ for different squeeze pressures $0,30,50,70,100$, and $130 \mathrm{MPa}$, respectively. The amount of heat transfer is observed in the melt and reinforcement based on the applied pressure [29]. Hence, the temperature is varied based on the applied pressure.

It is important to focus complex shape engineering application-oriented castings, using design and solidification process using the finite element method. FEA is significant for casting industry because components' rejection leads to increase in cost of production. The finite element method is better in analyzing heat transfer of components within the 


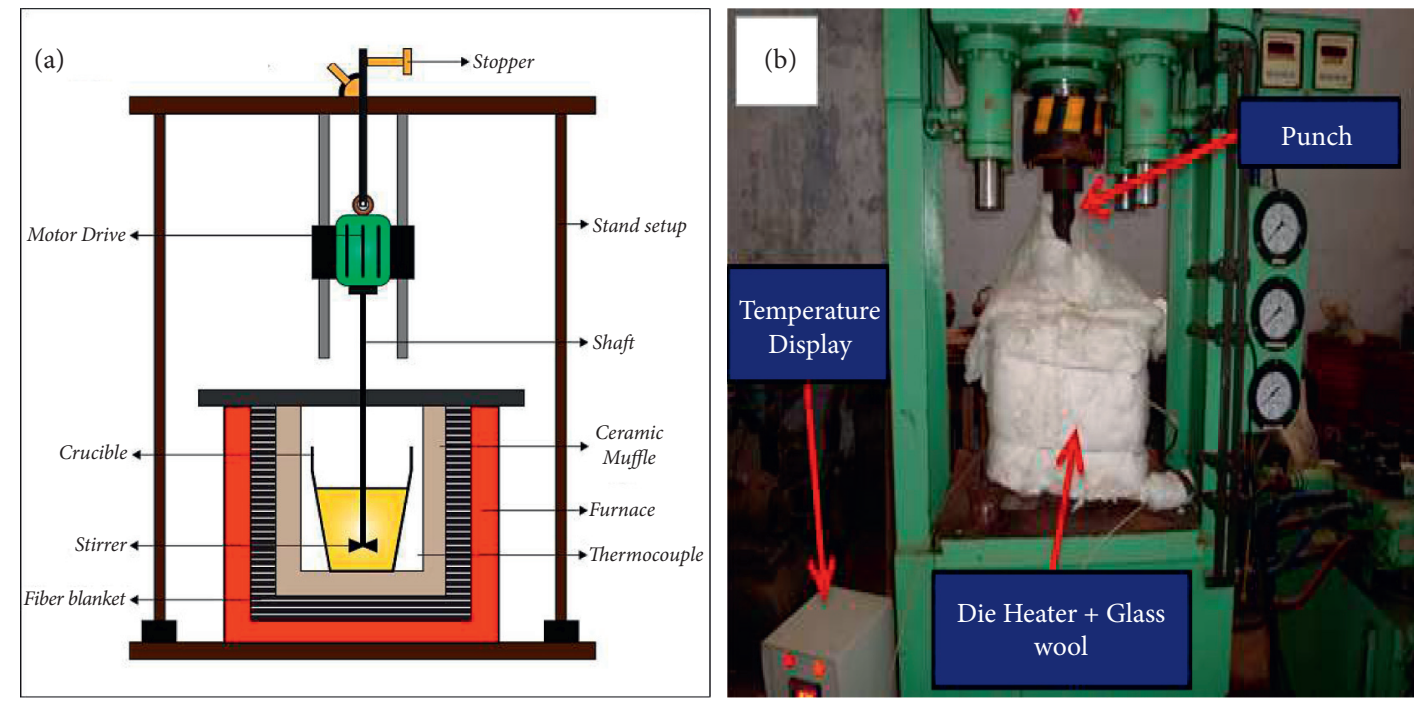

FIGURE 3: (a) Melt stirring setup. (b) Die and punch preheating for the preparation of composite.

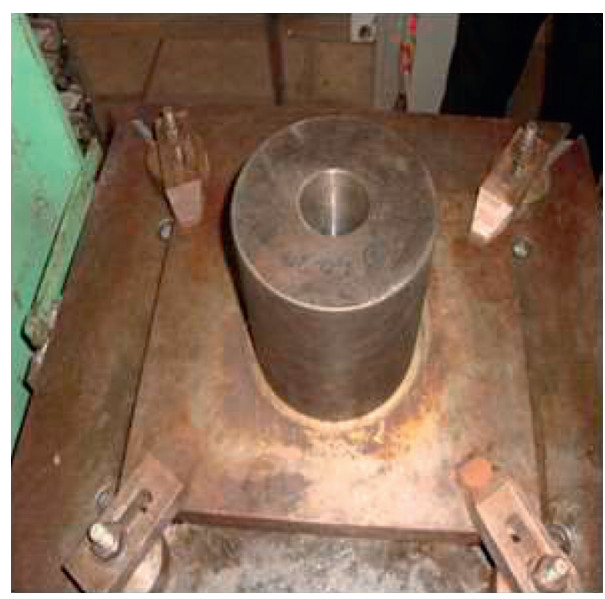

(a)

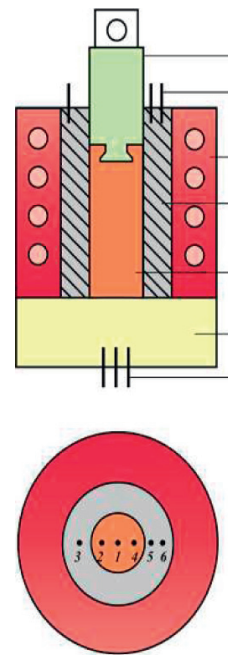

Thermocouple Position

1. Centre for the casting in the base plate.

2. $10 \mathrm{~mm}$ from the casting in the base plate. 3. $20 \mathrm{~mm}$ from the casting in the base plate. $4.3 \mathrm{~mm}$ from the interface in the die.

$5.6 \mathrm{~mm}$ from the interface in the die. 6. $9 \mathrm{~mm}$ from the interface in the die.

(c)

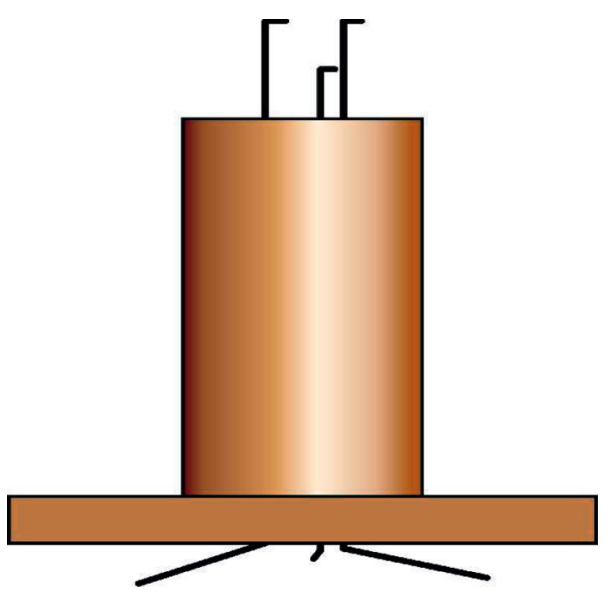

(b)

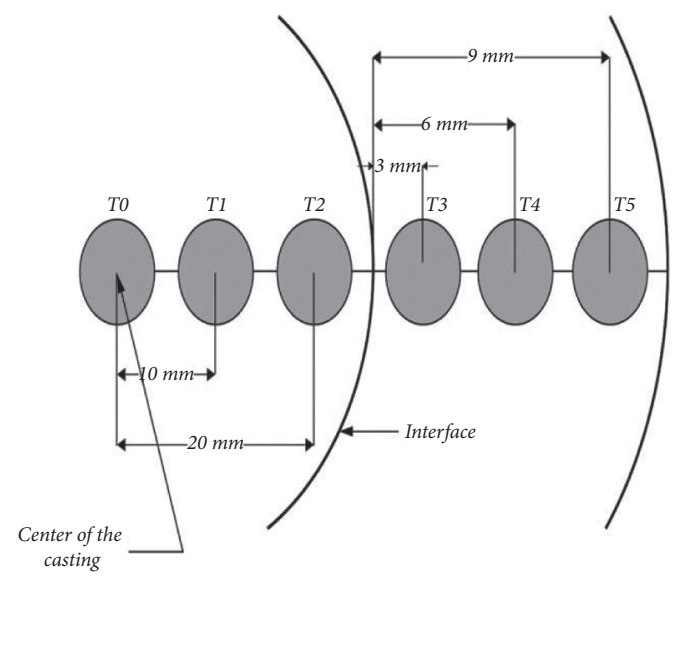

(d)

Figure 4: (a) Die and baseplate. (b) Appropriate locations of thermocouples for the complete setup. (c) Experimental squeeze cast setup. (d) Exact locations of thermocouples in the baseplate and die material. 


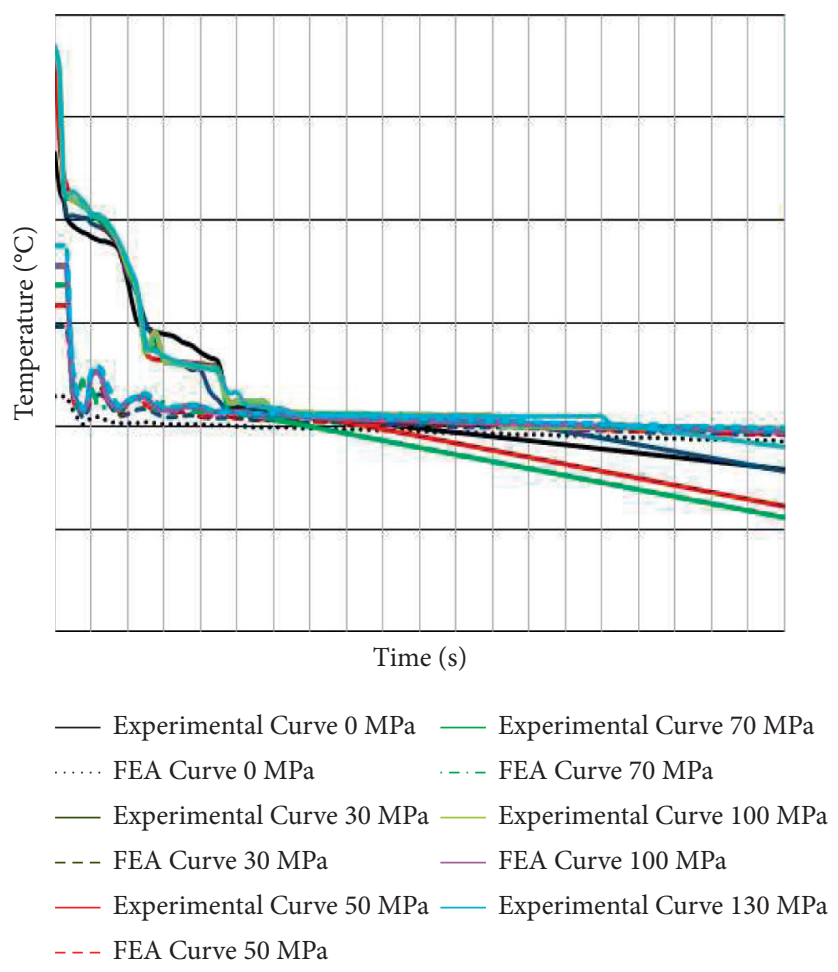

Figure 5: Comparison of experimental and FEA curves for $\mathrm{Al} \mathrm{AA6082/SiC}$ composites.
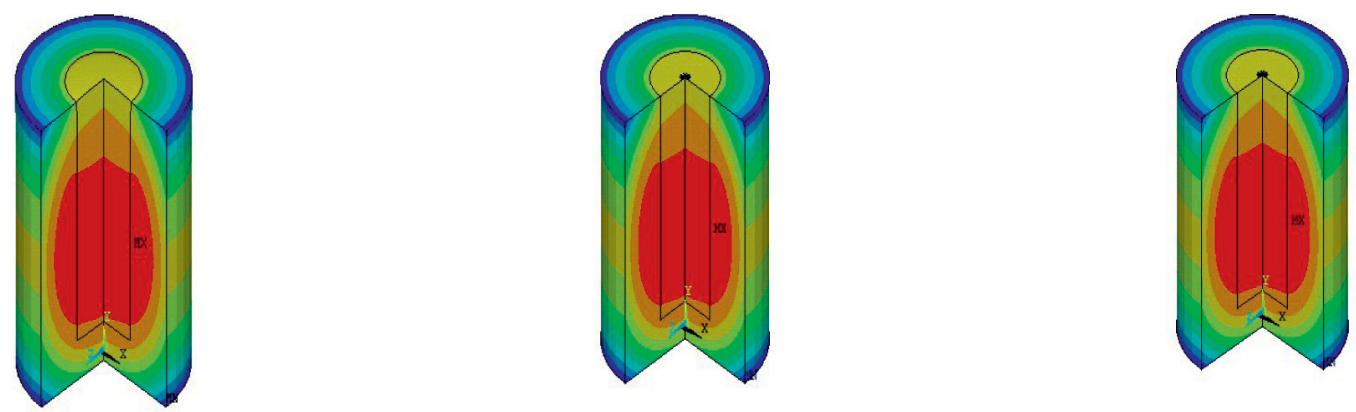

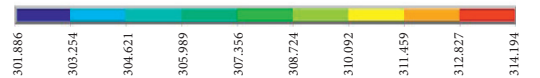

(a)
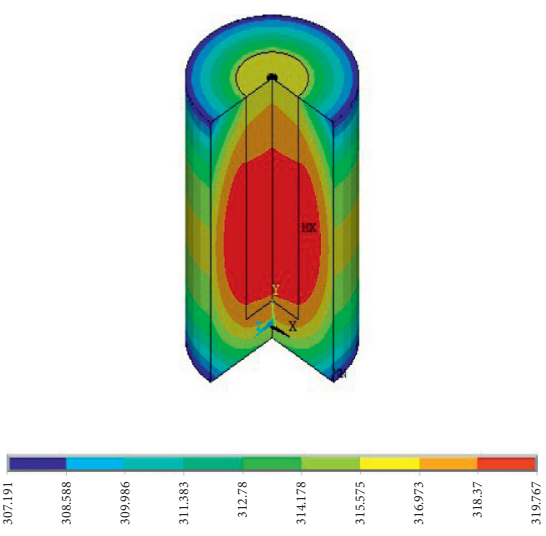

(d)

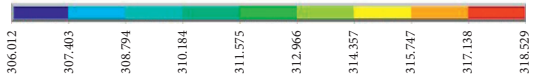

(b)
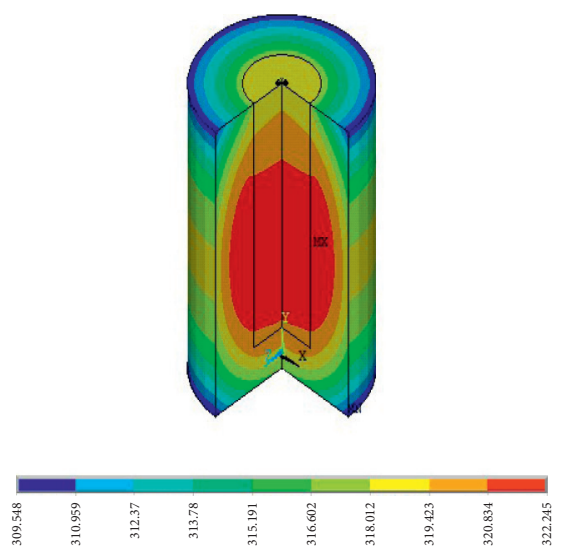

(e)

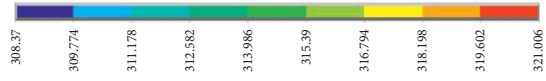

(c)
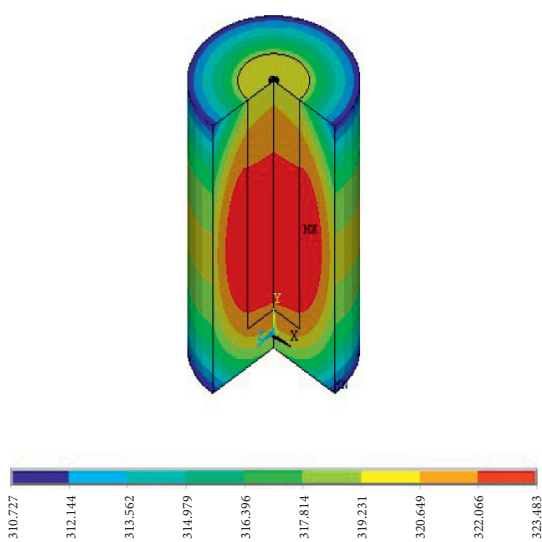

(f)

Figure 6: Temperature dispersion in the composites at various squeeze pressures up to 800 seconds: (a) $0 \mathrm{MPa}$; (b) $30 \mathrm{MPa}$; (c) $50 \mathrm{MPa}$; (d) $70 \mathrm{MPa}$; (e) $100 \mathrm{MPa}$; (f) $130 \mathrm{MPa}$. 


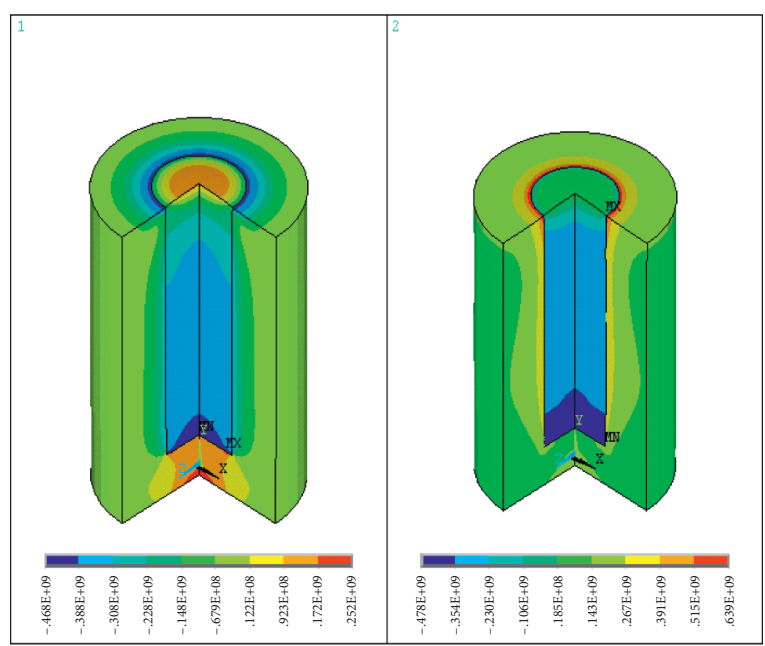

(a)

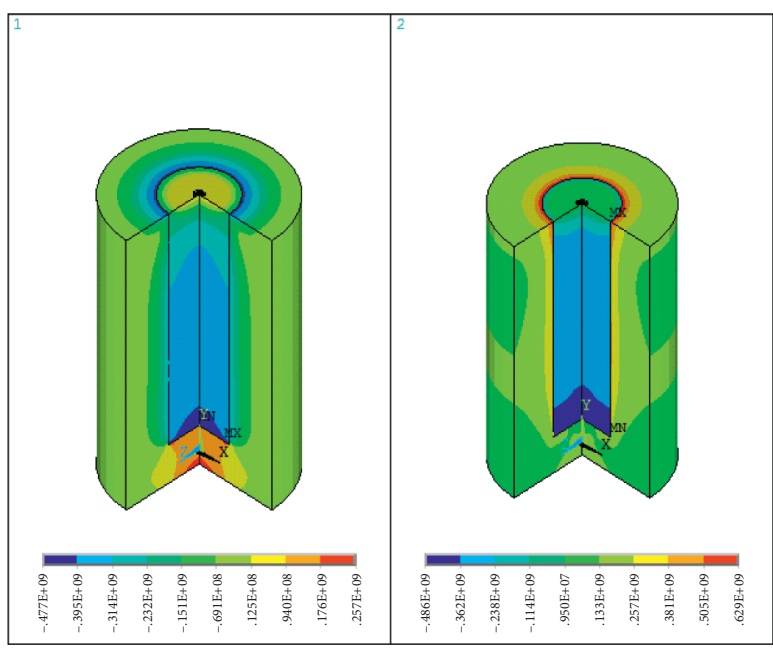

(c)

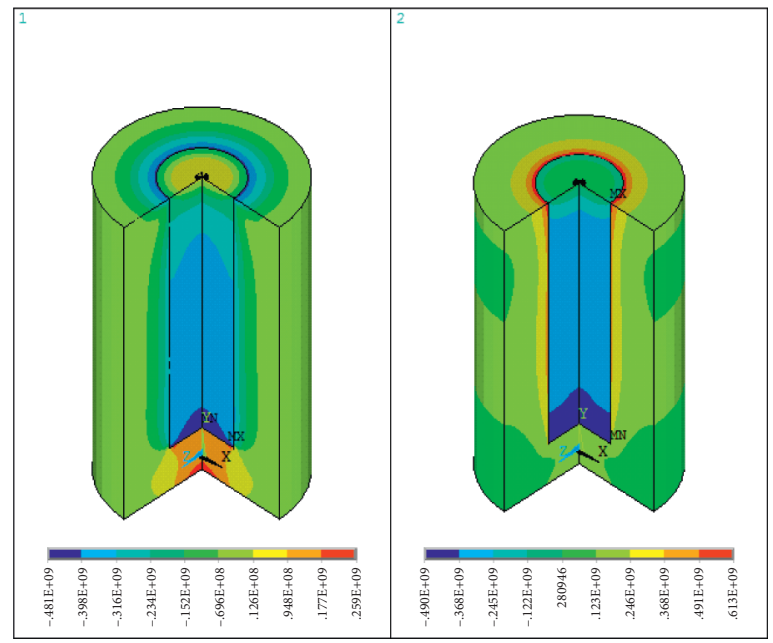

(e)

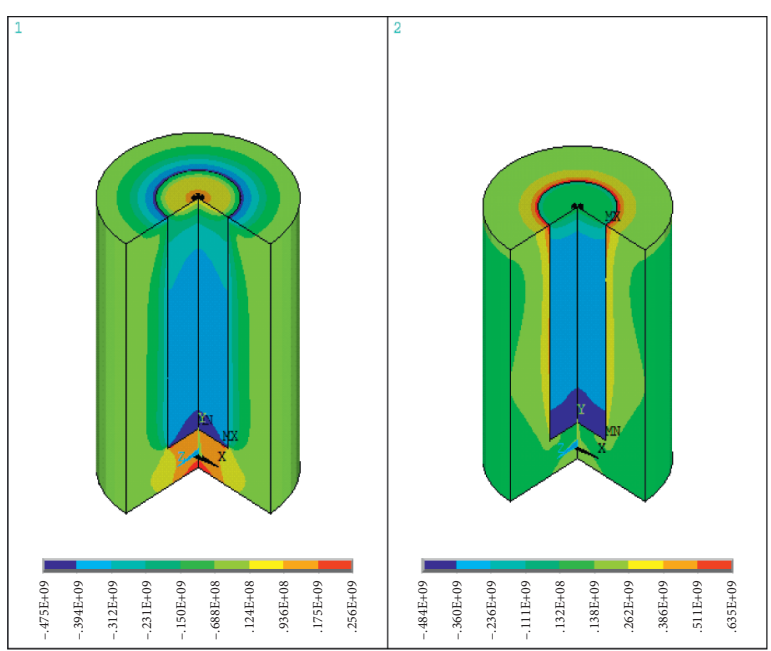

(b)

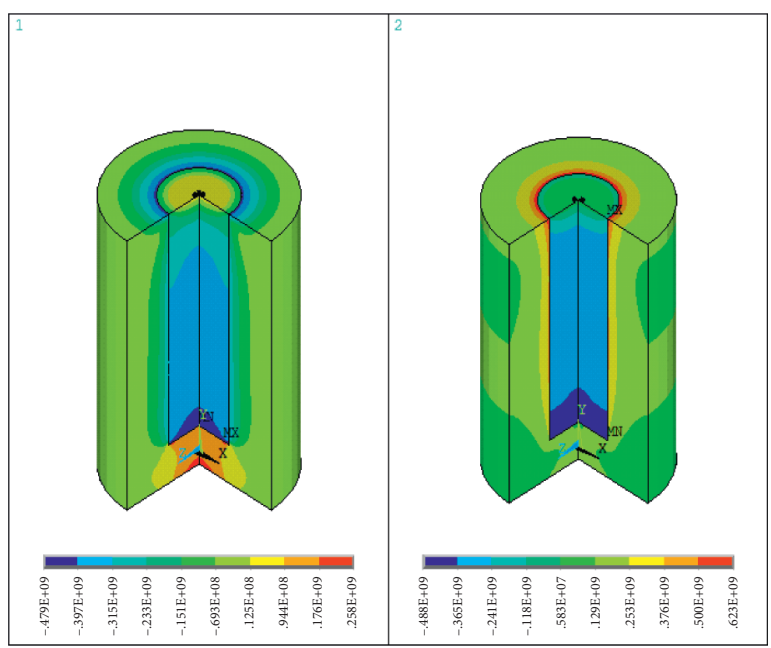

(d)

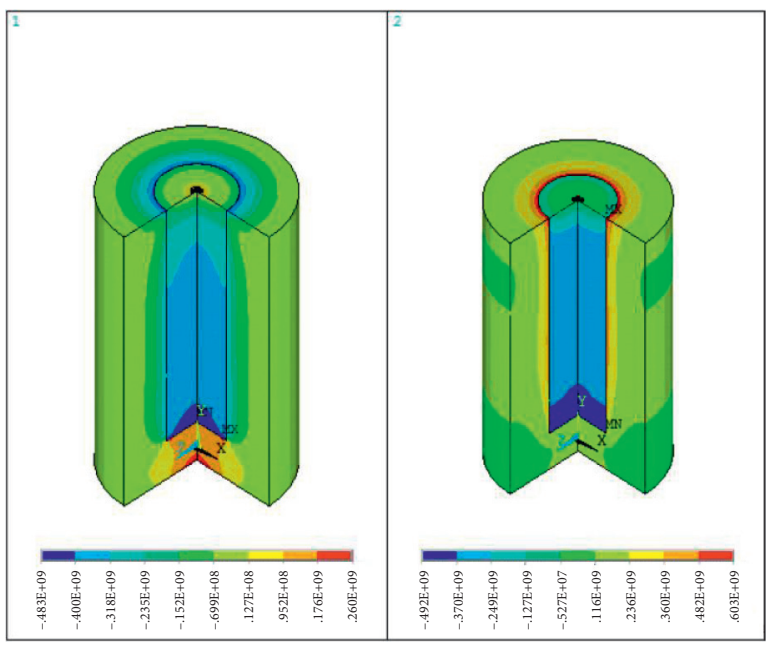

(f)

FIGURE 7: The radial and tangential stresses obtained with increasing squeeze pressures: (a) $0 \mathrm{MPa}$; (b) $30 \mathrm{MPa}$; (c) $50 \mathrm{MPa}$; (d) $70 \mathrm{MPa}$; (e) $100 \mathrm{MPa}$; (f) $130 \mathrm{MPa}$. 
TABLE 6: Stress dispersion of the squeeze cast composite for 800 seconds.

\begin{tabular}{lcccc}
\hline $\begin{array}{l}\text { Squeeze } \\
\text { pressure }(\mathrm{MPa})\end{array}$ & \multicolumn{2}{c}{$\begin{array}{c}\text { Radial stress } \\
(\mathrm{MPa})\end{array}$} & \multicolumn{2}{c}{$\begin{array}{c}\text { Tangential stress } \\
(\mathrm{MPa})\end{array}$} \\
& Max & Min & Max & Min \\
\hline 0 & 252 & -468 & 639 & -478 \\
30 & 256 & -475 & 635 & -483 \\
50 & 257 & -477 & 629 & -486 \\
70 & 258 & -479 & 623 & -488 \\
100 & 259 & -481 & 613 & -490 \\
130 & 260 & -483 & 603 & -492 \\
\hline
\end{tabular}

system and outside the system. In this analysis, the initial thermal stresses are kept at $0^{\circ} \mathrm{C}$, and it was considered that the composites' mechanical property values are taken as per the experimental work because the mechanical property values may change at higher temperature. With these constraints, the temperature (linear) distribution and tangential and radial stresses are plotted for the squeeze-cast specimen. The melt and reinforcements have different thermal expansions; hence, the study of radial and tangential stresses is essential in this analysis. Figure 7 shows the radial and tangential stresses obtained with increasing squeeze pressures. The application of pressure is in the axial direction; hence, the radial stresses are high at the bottom of the die. At the melt and die interface location, the tangential stress is maximum. Table 6 shows the stress dispersion of the squeeze cast composite for 800 seconds. Tangential stresses are comparatively higher than the radial stresses, and in the interfacial region, the tangential stresses are decreased [30]. It is due to the application pressure, which leads to a thermal mismatch within the composite [31]. Hence, the stresses are closely related to the orthotropic behavior of composite material.

\section{Conclusion}

The following observations are identified from the experimental and FEA analysis of an aluminium-based metal matrix composite.

(1) Experimental cooling rates are increased by increasing the squeeze pressure. The effect of pressure enhances the heat transfer rate of the melt and the die material.

(2) Predicted cooling rates are increased by increasing the pressure, but the values are almost close to experimental cooling rates.

(3) The amount of heat transfer is observed in the melt and reinforcement based on the applied pressure. Hence, the temperature is varied based on the applied pressure.

(4) Tangential stresses are comparatively higher than the radial stresses, and in the interfacial region, the tangential stresses are decreased. It is due to the application pressure, which leads to a thermal mismatch within the composite. Hence, the stresses are closely related to the orthotropic behaviour of composite material.
(5) Particle and base alloy reaction, the formation of air inside the mould, and flow velocity have to be considered for the FEA study.

\section{Data Availability}

The data used to support the findings of this study are included within the article.

\section{Disclosure}

This study was performed as a part of employment in Mizan Tepi University, Ethiopia

\section{Conflicts of Interest}

The authors declare that there are no conflicts of interest regarding the publication of this article.

\section{Acknowledgments}

The authors thank the Department of Mechanical Engineering, Chennai Institute of Technology, Chennai, and Centre for Materials Engineering and Regenerative Medicine, Bharath Institute of Higher Education and Research, Chennai, and this project was supported by researchers supporting project number (RSP-2021/257), King Saud University, Riyadh, Saudi Arabia.

\section{References}

[1] P. Gurusamy, S. B. Prabu, and R. Paskaramoorthy, "Influence of processing temperatures on mechanical properties and microstructure of squeeze cast aluminum alloy composites," Materials and Manufacturing Processes, vol. 30, no. 3, pp. 367-373, 2015.

[2] P. Gurusamy, S. B. Prabu, and R. Paskaramoorthy, "Interfacial thermal resistance and the solidification behavior of the $\mathrm{Al} /$ SiCpComposites," Materials and Manufacturing Processes, vol. 30, no. 3, pp. 381-386, 2015.

[3] P. Gurusamy, S. Balasivanandha Prabu, and R. Paskaramoorthy, "Prediction of Cooling Curves for Squeeze Cast $\mathrm{Al} / \mathrm{SiCp}$ Composites Using Finite Element Analysis," Metallurgical and Materials Transactions A, vol. 46, no. 4, pp. 1697-1703, 2015.

[4] M. R Ghomashchi and A. Vikhrov, "Squeeze casting: an overview," Journal of Materials Processing Technology, vol. 101, no. 1-3, pp. 1-9, 2000.

[5] T. M. Yue and G. A. Chadwick, "Squeeze casting of light alloys and their composites," Journal of Materials Processing Technology, vol. 58, no. 2-3, pp. 302-307, 1996.

[6] A. Fardi Ilkhchy, M. Jabbari, and P. Davami, "Effect of pressure on heat transfer coefficient at the metal/mold interface of A356 aluminum alloy," International Communications in Heat and Mass Transfer, vol. 39, no. 5, pp. 705-712, 2012.

[7] K. Sukumaran, K. K. Ravikumar, S. G. K. Pillai et al., "Studies on squeeze casting of Al 2124 alloy and 2124-10\% SiCp metal matrix composite," Materials Science and Engineering: A, vol. 490, no. 1-2, pp. 235-241, 2008.

[8] G. S. Hanumanth and G. A. Irons, "Solidification of particlereinforced metal-matrix composites," Metallurgical and Materials Transactions B, vol. 27, no. 4, pp. 663-671, 1996. 
[9] T. P. D. Rajan, K. Narayan Prabhu, R. M. Pillai, and B. C. Pai, "Solidification and casting/mould interfacial heat transfer characteristics of aluminum matrix composites," Composites Science and Technology, vol. 67, no. 1, pp. 70-78, 2007.

[10] W. Zhou, "Effectively enhanced load transfer by interfacial reactions in multi-walled carbon nanotube rein- forced $\mathrm{Al}$ matrix composites," Acta Materialia, vol. 125, pp. 369-376, 2016.

[11] W. Zhou, P. Mikulova, Y. Fan, K. Kikuchi, N. Nomura, and A. Kawasaki, "Interfacial reaction induced efficient load transfer in few-layer graphene reinforced Al matrix composites for high-performance conductor," Composites Part B: Engineering, vol. 167, pp. 93-99, 2019.

[12] G. Fan, Y. Jiang, Z. Tan et al., "Enhanced interfacial bonding and mechanical properties in CNT/Al composites fabricated by flake powder metallurgy," Carbon, vol. 130, pp. 333-339, 2018.

[13] M. Li, Z. Zhang, H. Gao et al., "Formation of multilayer interfaces and the load transfer in graphene nanoplatelets reinforced Al matrix composites," Materials Characterization, vol. 159, Article ID 110018, 2019.

[14] T. Han, E. Liu, J. Li, N. Zhao, and C. He, "A bottom-up strategy toward metal nano-particles modified graphene nanoplates for fabricating aluminum matrix composites and interface study," Journal of Materials Science \& Technology, vol. 46, pp. 21-32, 2020.

[15] Y. Liu, Y. Ma, W. Liu et al., "The mechanical properties and formation mechanism of $\mathrm{Al} / \mathrm{Mg}$ composite interface prepared by spark plasma sintering under different sintering pressures," Vacuum, vol. 176, Article ID 109300, 2020.

[16] M. R. Ghomashchi and K. N. Strafford, "Factors influencing the production of high integrity alu- minium/silicon alloy components by die and squeeze casting processes," Journal of Materials Processing Technology, vol. 38, no. 1-2, pp. 303-326, 1993.

[17] I. Alfonso, O. Navarro, J. Vargas et al., "FEA evaluation of the Al4C3 formation effect on the Young's modulus of carbon nanotube reinforced aluminum matrix composites," Composite Structures, vol. 127, pp. 420-425, 2015.

[18] G. Li, X. Zhang, Q. Fan et al., "Simulation of damage and failure processes of interpenetrating $\mathrm{SiC} / \mathrm{Al}$ composites subjected to dynamic compressive loading," Acta Materialia, vol. 78, pp. 190-202, 2014.

[19] T. R. Vijayaram, S. Sulaiman, A. M. S. Hamouda, and M. H. M. Ahmad, "Numerical simulation of casting solidification in permanent metallic molds," Journal of Materials Processing Technology, vol. 178, no. 1-3, pp. 29-33, 2006.

[20] V. Mohanavel, K. Rajan, and M. Ravichandran, "Synthesis, characterization and properties of stir cast AA6351-aluminium nitride (AlN) composites," Journal of Materials Research, vol. 31, no. 24, pp. 3824-3831, 2016.

[21] S. K. Jagadeesh, C. S. Ramesh, J. M. Mallikarjuna, and R. Keshavamurthy, "Prediction of cooling curves during solidification of Al 6061-SiCp based metal matrix composites using finite element analysis," Journal of Materials Processing Technology, vol. 210, no. 4, pp. 618-623, 2010.

[22] V. Mohanavel, K. S. Ashraff Ali, S. Prasath, T. Sathish, and M. Ravichandran, "Microstructural and tribological characteristics of AA6351/Si3N4 composites manufactured by stir casting," Journal of Materials Research and Technology, vol. 9, no. 6, Article ID 14662, 2020.

[23] J. Zhang, Q. Ouyang, Q. Guo et al., "3D Microstructure-based finite element modeling of deformation and fracture of SiCp/
Al composites," Composites Science and Technology, vol. 123, pp. 1-9, 2016.

[24] J. Nafar Dastgerdi, B. Anbarlooie, A. Miettinen, H. Hosseini Toudeshky, and H. Remes, "Effects of particle clustering on the plastic deformation and damage initiation of particulate reinforced composite utilizing X-ray CT data and finite element modeling," Composites Part B: Engineering, vol. 153, pp. 57-69, 2018.

[25] X. Tan, B. Zhang, K. Liu et al., "Microstructure and mechanical property of the $2024 \mathrm{Al}$ matrix hybrid composite reinforced with recycled SiCp/2024Al composite particles," Journal of Alloys and Compounds, vol. 815, Article ID 152330, 2020.

[26] L. J. Yang, "The effect of solidification time in squeeze casting of aluminium and zinc alloys," Journal of Materials Processing Technology, vol. 192-193, pp. 114-120, 2007.

[27] Y. Seo and C. Kang, "The effect of applied pressure on particledispersion characteristics and mechanical properties in meltstirring squeeze-cast $\mathrm{SiCp} / \mathrm{Al}$ composites," Journal of Materials Processing Technology, vol. 55, no. 3-4, pp. 370-379, 1995.

[28] A. Maleki, B. Niroumand, and A. Shafyei, "Effects of squeeze casting parameters on density, macrostructure and hardness of LM13 alloy," Materials Science and Engineering: A, vol. 428, no. 1-2, pp. 135-140, 2006.

[29] M. S. Yong and A. J. Clegg, "Process optimisation for a squeeze cast magnesium alloy," Journal of Materials Processing Technology, vol. 145, no. 1, pp. 134-141, 2004.

[30] G. Altan and M. Topçu, "Thermo-elastic stress of a metalmatrix composite disc under linearly-increasing temperature loading by analytical and FEM analysis," Advances in Engineering Software, vol. 41, no. 4, pp. 604-610, 2010.

[31] L. Cen, W. Y. Qin, and Q. M. Yu, "Analysis of interface delamination in thermal barrier coating system with axisymmetric structure based on corresponding normal and tangential stresses," Surface and Coatings Technology, vol. 358, pp. 785-795, 2019. 